\title{
Spontaneous Seizures and Altered Gene Expression in GABA Signaling Pathways in a mind bomb Mutant Zebrafish
}

\author{
Gabriela A. Hortopan, Matthew T. Dinday, and Scott C. Baraban \\ Epilepsy Research Laboratory, Department of Neurological Surgery, University of California, San Francisco, San Francisco, California 94143
}

Disruption of E3 ubiquitin ligase activity in immature zebrafish mind bomb mutants leads to a failure in Notch signaling, excessive numbers of neurons, and depletion of neural progenitor cells. This neurogenic phenotype is associated with defects in neural patterning and brain development. Because developmental brain abnormalities are recognized as an important feature of childhood neurological disorders such as epilepsy and autism, we determined whether zebrafish mutants with grossly abnormal brain structure exhibit spontaneous electrical activity that resembles the long-duration, high-amplitude multispike discharges reported in immature zebrafish exposed to convulsant drugs. Electrophysiological recordings from agar immobilized mind bomb mutants at $3 \mathrm{~d}$ postfertilization confirmed the occurrence of electrographic seizure activity; seizure-like behaviors were also noted during locomotion video tracking of freely behaving mutants. To identify genes differentially expressed in the mind bomb mutant and provide insight into molecular pathways that may mediate these epileptic phenotypes, a transcriptome analysis was performed using microarray. Interesting candidate genes were further analyzed using conventional reverse transcriptase-PCR and real-time quantitative PCR, as well as whole-mount in situ hybridization. Approximately 150 genes, some implicated in development, transcription, cell metabolism, and signal transduction, are differentially regulated, including downregulation of several genes necessary for GABA-mediated signaling. These findings identify a collection of gene transcripts that may be responsible for the abnormal electrical discharge and epileptic activities observed in a mind bomb zebrafish mutant. This work may have important implications for neurological and neurodevelopmental disorders associated with mutations in ubiquitin ligase activity.

\section{Introduction}

Notch is an essential component of an evolutionarily conserved signal transduction cascade mediating development. In neuroectoderm, in which cells have the potential to become neurons, activated Notch inhibits proneural gene expression in a process referred to as lateral inhibition. In the absence of Notch-mediated lateral inhibition, too many early-born cells differentiate into neurons (Chitnis et al., 1995; de la Pompa et al., 1997). Recent studies identified several E3 ligases that modulate Notch signaling through ubiquitin-dependent protein degradation and endocytosis (Lai, 2002). Ubiquitination, which occurs when an E3 ligase enzyme binds to both substrate and an E2 thioesterified protein (Deshaies and Joazeiro, 2009), is a key mechanism regulating many cellular processes. Mutation or small deletions within the ubiquitin E3A ligase gene in humans has been linked to autism spectrum disorders (Glessner et al., 2009) and Angelman syndrome, a neurogenetic disorder characterized by developmental delay, severe intellectual disability, absent speech, exuberant behavior, motor impairment, and epilepsy (ClaytonSmith and Laan, 2003).

Received April 13, 2010; revised May 6, 2010; accepted May 22, 2010.

This work was supported by an National Institutes of Health R01 Grant NS053479-03 (S.C.B.). We thank Dan Lowenstein and Joy Sebe for comments on previous versions of this manuscript and Sally Chege for assistance with in situ hybridization studies.

Correspondence should be addressed to S. C. Baraban, Department of Neurological Surgery, University of California, San Francisco, Box 0112, 513 Parnassus Avenue, San Francisco, CA 94143. E-mail: scott.baraban@ucsf.edu. DOI:10.1523/JNEUROSCI.1887-10.2010

Copyright $\odot 2010$ the authors $\quad 0270-6474 / 10 / 3013718-11 \$ 15.00 / 0$
Mutations in several zebrafish mind bomb (mib) mutants disrupt E3 ubiquitin ligase activity (Schier et al., 1996; Itoh et al., 2003). Here we used a zebrafish insertional mutant $\left(m_{i b} b^{h i 904}\right)$ that is allelic to the chemically induced mib mutants ( $m i b^{t a 52 b}, m_{i b} b^{m 132}$, and $m i b^{t f i 91}$ ). Defects in $\mathrm{mib}^{\text {hi }}{ }^{\mathrm{c} 4}$ are the result of a retroviral insertion in an exon of the zebrafish homolog of the human KIAA1323 gene (Golling et al., 2002; Chen and Casey Corliss, 2004) showed that Hi904 mutation disrupts a conserved putative E3 ubiquitin ligase that regulates Notch signaling. In mib mutants, there is an excess production of early-born neurons and a concomitant reduction in the number of late-born neurons. At $2 \mathrm{~d}$ postfertilization (dpf), the developing spinal cord and hindbrain is nearly filled with $h u C$, an early neuronal differentiation marker (Itoh et al., 2003; Park and Appel, 2003) and an overabundance of early differentiating Rohon-Beard neurons (Bingham et al., 2003). Consistent with a lateral inhibition neurogenic phenotype, late-differentiating secondary islet green fluorescent protein-expressing motor neurons and gata3-expressing interneurons are decreased in the mib hindbrain (Bingham et al., 2003). Genome-wide analysis of mind bomb mutants was performed recently to identify Notch-responsive genes required for pancreatic (Hegde et al., 2008) or mesodermic (Hwang et al., 2009) development. However, identification of differentially regulated CNS genes was not discussed, and little is presently known about the functional or behavioral consequences of a defect in E3 ubiquitin ligase activity in mib $^{\text {hi } 904}$ mutants.

Here we present a phenotypic characterization of mind bomb mutant zebrafish. Electrophysiological analysis shows that mib ${ }^{\text {higo4 }}$ mutants exhibit spontaneous epileptiform-like burst 
Table 1. Primers used for $q P C R$ assay

\begin{tabular}{|c|c|c|c|c|}
\hline Gene name & Gene symbol & GenBank & Sequence & Amplicon (bp) \\
\hline$\beta$-Actin & $\beta$-act & FJ915059 & $\begin{array}{l}\text { F, 5'CATCCATCGTTCACAGGAAGTG 3' } \\
\text { R, 5' } 5^{\prime} \text { TGGTCGTTCGTTTGAATCTCAT 3' }\end{array}$ & 83 \\
\hline 185 ribosomal & 185 & FJ915075 & $\begin{array}{l}\text { F, 5'ACGAGACTCCGGCATGCTA 3' } \\
\text { R, 5' TGGCTGAACGCCACTTGTC 3' }\end{array}$ & 84 \\
\hline Elongation factor $1 \alpha$ subunit & EF1a & FJ915061 & $\begin{array}{l}\text { F, 5'CTGCCAGTGTTGCCTTCGT 3' } \\
\text { R, 5'CCTTGCGCTCAATCTTCCA 3' }\end{array}$ & 105 \\
\hline$\beta-2$ microglobulin & $b 2 m$ & FJ915076 & $\begin{array}{l}\text { F, 5' TGCAGCGTTCGACACATGA 3' } \\
\text { R, 5' } 5^{\prime} \text { 'ACGAATCCATCGCTCCAT 3' }\end{array}$ & 102 \\
\hline Brain-derived neurotrophic factor & Bdnf & FJ915060 & $\begin{array}{l}\text { F, } 5^{\prime} \text { TCGAAGGACGTTGACCTGTATG 3' } \\
\text { R, } 5^{\prime} \text { TGGCGGCATCCAGGTAGT 3' }\end{array}$ & 112 \\
\hline Peptide YYa & Pyy & FJ915073 & $\begin{array}{l}\text { F, 5' TCCTCATCTGCGTGCTTCTGT 3' } \\
\text { R, 5'GCGGTGTAATATTTGGCGAGTT 3' }\end{array}$ & 112 \\
\hline Calbindin 2 & calb2 & FJ915062 & $\begin{array}{l}\text { F, 5'ACGACAAGGATGGCAATGGT 3' } \\
\text { R, 5'AGCGCCATGATGCTCTTCTT 3' }\end{array}$ & 130 \\
\hline $\mathrm{GABA}_{A}$ receptor, $\alpha 1$ & gabra1 & FJ915065 & $\begin{array}{l}\text { F, 5' TCAGGCAGAGCTGGAAGGAT } 3^{\prime} \\
\text { R, 5'TGCCGTTGTGGAAGAACGT 3' }\end{array}$ & 117 \\
\hline Glutamate decarboxylase 1 & gad1 & FJ915066 & $\begin{array}{l}\text { F, 5'AACTCAGGCGATTGTTGCAT 3' } \\
\text { R, 5' TGAGGACATTTCCAGCCTTC } 3^{\prime}\end{array}$ & 109 \\
\hline Glycine receptor $\alpha Z 4$ subunit & glra4b & FJ915068 & $\begin{array}{l}\text { F, 5' } \text { S'TCTGAAGCTGCTGCCATGTT 3' }^{\prime} \\
\text { R, 5' } \text { 5ATCCGTTTGGCTTGTTCCA 3' }^{\prime}\end{array}$ & 91 \\
\hline Parvalbumin isoform 2a & pvalb5 & FJ915072 & $\begin{array}{l}\text { F, 5'GAATCATGGCACTTGCAGGAA 3' } \\
\text { R, 5' TGAAAGATCCTTGCGCTTGAC 3' }\end{array}$ & 81 \\
\hline
\end{tabular}

Real-time qPCR primer sequences, GenBank accession number, and amplicon size for the seven genes of interest and the four endogenous genes used in SYBR Green assay. F, Forward; $R$, reverse.

discharge similar to that obtained after exposure to a convulsant drug. Video observation and locomotion tracking indicates the occurrence of seizure-like behaviors (Baraban et al., 2007; Berghmans et al., 2007). Additionally, microarray analysis, quantitative realtime PCR (qPCR), and whole-mount in situ hybridization (WISH) identified a downregulation of several genes associated with GABAmediated synaptic transmission.

\section{Materials and Methods}

Animals and maintenance. Adult male and female zebrafish (mind bomb, line hi904; mind bomb, line ta52b; t-complex polypeptide 1, line hi3564; histone deacetylase 1, line hi1618; denticleless homolog, line hi447) were obtained from the Zebrafish International Resource Center (Eugene, OR; http://zebrafish.org/zirc/fish/lineAll.php). Adult zebrafish were maintained according to standard procedures (Westerfield, 1993) and following guidelines approved by the University of California, San Francisco Institutional Animal Care and Use Committee. Zebrafish embryos and larvae were maintained in egg water $(0.03 \%$ Instant Ocean) unless otherwise stated.

Electrophysiology. To obtain stable physiological recordings, zebrafish larvae at $3 \mathrm{dpf}$ were immobilized in $1.2 \%$ low-melting temperature agarose in zebrafish egg water. Larvae were embedded so that the dorsal aspect of the brain was accessible for electrode placement. Embedded larvae were bathed in egg water and visualized using an Olympus BX50 microscope (Olympus America). Under direct visual guidance, a glass microelectrode $(<1.2 \mathrm{~mm}$ tip diameter, $2-7 \mathrm{M} \Omega$ ) was placed in the forebrain or optic tectum. Electrodes were filled with $2 \mathrm{M} \mathrm{NaCl}$, and electrical activity was recorded using an Axopatch 1D amplifier (Molecular Devices). Voltage records were low-pass filtered at $1-2 \mathrm{kHz}(-3 \mathrm{~dB}$, eight-pole Bessel), high-pass filtered at $0.1-0.2 \mathrm{~Hz}$, digitized at $5-10 \mathrm{kHz}$ using a Digidata 1300 analog-to-digital interface, and stored on a personal computer running pClamp software (Molecular Devices).

Electrophysiological recordings were analyzed post hoc using Clampfit software (Molecular Devices). Spontaneous gap-free recordings, 15-30 min in duration, were analyzed for all fish $(n=75)$. A threshold for detection of spontaneous events was set at three times noise (peak-topeak amplitude) and $100 \mathrm{~ms}$ (duration); all events exceeding these thresholds were analyzed.

Behavioral monitoring. For locomotion tracking, single zebrafish larvae were placed individually in 96-well Falcon culture dishes (BD Biosciences). Each well contained $70 \mu \mathrm{l}$ of embryo medium. Swimming behavior was monitored at $3 \mathrm{dpf}$ for $10 \mathrm{~min}$ in wild-type (WT) larvae $(n=22)$ and mib mutant larvae $(n=28)$ using a CCD camera (Hamamatsu C-2400) and EthoVision 3.1 locomotion tracking software (Noldus Information). Locomotion plots were categorized by two observers blind to larvae phenotype as displaying class 0 (no movement, baseline activity), class 1 (small increase in movement), or class 3 (considerable movement, convulsive behavior) activity (Baraban et al., 2005). Using Ethovision software (Noldus Information), the percentage of time spent swimming/moving was analyzed for individual locomotion plots.

RNA extraction, hybridization, scanning, analysis, and gene categorization. A total of six microarrays were hybridized to compare gene expression patterns between mib mutants $(n=3)$ and age-matched WT sibling controls $(n=3)$, including a dye swap for each tissue; each microarray used RNA pooled from 10 zebrafish larvae. At $3 \mathrm{dpf}$, larvae were sorted by morphology and total RNA was extracted using Trizol Reagent (Invitrogen), treated with DNase (Ambion/Applied Biosystems), and quantified with GeneQuant spectrophotometer. An Agilent Bioanalyser 2100 (Agilent Technologies) was used to assess the integrity/quality of mRNA.

Hybridization, scanning, and analysis were completed by the National Institutes of Health Neuroscience Micro-Array Consortium (http:// arrayconsortium.tgen.org/np2/home.do) using an Affymetrix zebrafish genome array with $\sim 14,900$ Danio rerio transcripts. Different internal quality controls were used, including hybridization controls (BioB, BioC, BioD, and cre), poly A controls (dap, lys, phe, and thr), and "housekeeping" control genes (glyceraldehyde-3-phosphate dehydrogenase and $\alpha 1$ actin). Sequence information for this array was selected from the following public data sources: RefSeq (July 2003), GenBank (release 136.0, June 2003), dbEST (July 2003), and UniGene (Build 54, June 2003). Probe sets on the array were designed with 16 oligonucleotide pairs to detect each transcript. Affymetrix Gene Chip Operation Software (GCOS) version 1.4 was used to analyze the resulting image files. The global scaling technique was used to scale the fluorescence intensity of each chip to a target signal of 150. The data files (CEL files), resulting from analysis with the Affymetrix GCOS software, were imported into GeneSpring GX 7.3.1 software (Agilent Technologies) for additional data analysis.

Transcripts were considered as differentially expressed using multiple nonparametric two-tailed unpaired Student's $t$ test with a Benjamin Hochberg multitest correction (GeneSpring GX 7.3.1). $p \leq 0.05$ was considered to be significant. Hierarchical clustering (GeneTree) was applied to the data files. Categorization of genes identified by microarray analysis was performed using GO (Gene Ontology) Slim terms. 
PCR, cloning, and sequencing. Several genes of interest were chosen for additional analysis. One microgram of DNase-treated total RNA from whole zebrafish (10 fish per pool) was reversed transcribed (SuperScriptIII FirstStrand Synthesis System; Invitrogen) using a mix of oligo- $\mathrm{dT}_{20}$ and random hexamers. Two sets of primers pairs, forward and reverse, were specifically designed using Primer 3 web software (http://frodo.wi.mit.edu/primer3/) for each investigated gene to obtain a longer sequence (primers sequences are available in supplemental Table 1, available at www. jneurosci.org as supplemental material). The most conserved regions were identified by sequence alignment (ClustalW) (Thompson et al., 1994) of all available gene sequences from GenBank, including other fish species (Cyprinus carpio, Carassius auratus, Dicentrarchus labrax, Oncorhynchus mykiss, Salmo salar, etc.). Investigation of primer cross-specificity was done using BLAST (basic local alignment search tool) software. The predicted secondary structure of the entire DNA sequence was checked using Mfold software (http://frontend. bioinfo.rpi.edu/applications/mfold) (Zuker, 2003). Each reaction cycle (32 loops) consisted of incubations at $94^{\circ} \mathrm{C}(30 \mathrm{~s}), 60^{\circ} \mathrm{C}(30 \mathrm{~s})$, and $72^{\circ} \mathrm{C} \quad(60$ s) with TaqDNA Polymerase (TaqPCR Core kit; Qiagen). PCR products were separated by agarose (2\%) gel electrophoresis, stained with ethidium bromide, and cloned in pCRII-TOPO plasmid vector (TOPO TA Cloning System; Invitrogen). DNA sequencing was performed by Elim Biopharmaceuticals.

Whole-mount in situ hybridization. For antisense and sense RNA probes, the plasmids corresponding to each gene were linearized with appropriate restriction enzymes (HindIII, SpeI or BamHI, and NotI, XbaI, or ApaI; New England Biolabs).

The linearized DNA template $(1 \mu \mathrm{g})$ was purified (QIAquick; Qiagen) and incubated for $3 \mathrm{~h}$ at $37^{\circ} \mathrm{C}$ in a solution containing $10 \times$ transcription buffer, dithiothreitol (100 mM), 10X Dig NTP Mix (Roche), RNase inhibitor (20 $\mathrm{U} / \mu \mathrm{l})$, and RNA polymerase $(20 \mathrm{U} / \mu \mathrm{l}) \mathrm{T} 7$ or SP6. The DNA template was digested with DNase $(10 \mathrm{U} / \mu \mathrm{l})$ for $15 \mathrm{~min}$ at $37^{\circ} \mathrm{C}$. After incubation, $30 \mu \mathrm{l}$ of RNase-free water and $30 \mu \mathrm{l}$ of $\mathrm{LiCl}$ were added for purification and left overnight at $-20^{\circ} \mathrm{C}$. After centrifugation at $4^{\circ} \mathrm{C}$, the pellet was rinsed with $70 \%$ ethanol (RNase free), dried, and stored in hybridization mix at $-20^{\circ} \mathrm{C}$ until hybridization.

Embryos ( $3 \mathrm{dpf}$ ) were fixed in $4 \%$ paraformaldehyde and then stored in $100 \%$ methanol at $-20^{\circ} \mathrm{C}$. In situ RNA hybridization was performed as described previously (Hauptmann and Gerster, 1994). Once developed, the embryos were mounted in $70 \%$ glycerol for whole-mount imaging. All images were captured using a Carl Zeiss Axioskop microscope equipped with a Nikon E995 or Optronics MicroFire digital camera. Raw images were imported into Adobe Photoshop (Adobe Systems) and adjusted regarding the level of brightness, contrast, and cropping.

Quantitative real-time PCR. Gene expression levels of seven chosen genes were examined using RNA pooled from $10 \mathrm{WT}$ sibling larvae $(n=6)$ or 10 mib mutant larvae $(n=6)$. RNA was extracted in the same manner as for microarray experimentation (above) and reverse-transcription reactions (RT-PCR) were performed in the same manner as for cloning and sequencing using SuperScriptIII First-Strand Synthesis System (Invitrogen). The cDNA templates were diluted 1:2 with DEPC sterile water
2 forebrain
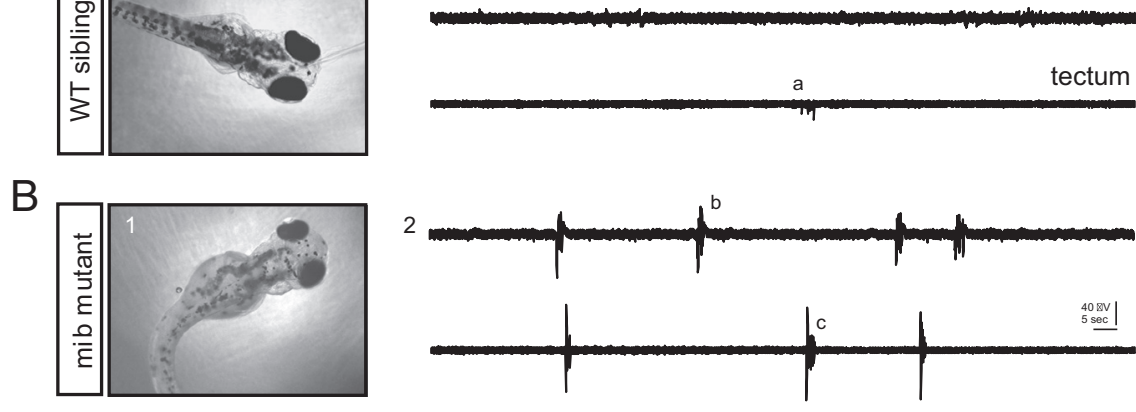
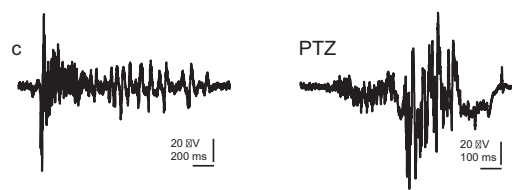

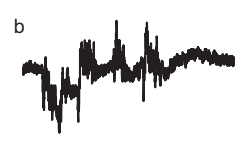

mib

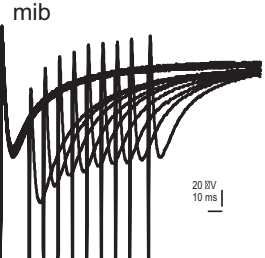

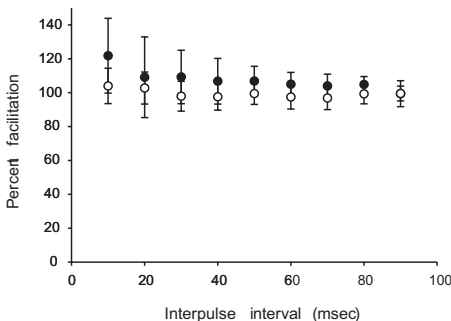

Figure 1. Seizures in immature mind bomb zebrafish. $\boldsymbol{A}$ 1, Representative image of an agar immobilized wild-type sibling zebrafish at $3 \mathrm{dpf}$. Note the patch recording electrode, at right, placed in the forebrain. A2, Gap-free extracellular field recordings a the zebrafish optic tectum. Note the extracellular field recordings from two different mib ${ }^{\text {higo4 }}$ mutant zebrafish recorded in normal embryo medium. Top trace reprerecording from the zebrafish forebrain; same fish as in $\boldsymbol{B 1}$. Bottom trace represents a typical recording from the gap-free recordings shown in $\boldsymbol{A}$ and $\boldsymbol{B}: \boldsymbol{a}$, brief burst of synchronized activity; $\boldsymbol{b}$, long-duration high-amplitude burst; $\boldsymbol{c}$ longstimulation (10-90 s interpulse interval) of the contralateral eye. Paired-pulse facilitation at brief interpulse intervals $(10-40 \mathrm{~s})$ WT control; open circles, mib. Data are shown as the mean \pm SEM.

before $\mathrm{qPCR}$ applications to minimize the presence of potential inhibitors.

The qPCR reactions were performed using SYBR Green fluorescent master mix on an ABI Prism 7700 Sequence Detection System driven by ABI prism SDS version 9.1 (Applied Biosystems). Primers were designed to produce amplicons ranging in size between 81 and $130 \mathrm{bp}$ (Table 1) using Primer Express version 3.0 (Applied Biosystems). All primers were synthesized by Invitrogen. Samples were run in triplicate and contained $1 \times$ SYBR Green master mix, $10 \mu \mathrm{M}$ of each primer, and RNase-free water for a final volume of $10 \mu$ l. Samples without reverse transcriptase and samples without RNAs were run for each reaction as negative controls. Cycling parameters were as follows: $50^{\circ} \mathrm{C}$ for $2 \mathrm{~min}, 95^{\circ} \mathrm{C}$ for $10 \mathrm{~min}$, and then 40 cycles of $95^{\circ} \mathrm{C}$ for $15 \mathrm{~s}$ and $60^{\circ} \mathrm{C}$ for $1 \mathrm{~min}$. For each sample, a dissociation step was performed at $95^{\circ} \mathrm{C}$ for $15 \mathrm{~s}, 60^{\circ} \mathrm{C}$ for $20 \mathrm{~s}$, and $95^{\circ} \mathrm{C}$ for $15 \mathrm{~s}$ at the end of the amplification phase to check for the presence of primer dimmers or nonspecific products (supplemental Fig. 1, available at www.jneurosci.org as supplemental material).

Triplicate quantification values [cycle threshold (CT)], provided from real-time qPCR instrumentation, were imported into a Microsoft Excel 
spreadsheet for additional analysis. Raw data were analyzed using qCalculator software (programmed by Ralf Gilsbach, Institute of Pharmacology and Toxicology, University of Bonn, Bonn, Germany) that estimates qPCR efficiency, $E=10(-1 /$ slope $)$, and the relative gene expression between samples after normalization with the most reliable endogenous gene (EndG) basing on both the comparative $\Delta \Delta \mathrm{CT}$ (Livak and Schmittgen, 2001) and the efficiency-based (Pfaffl, 2001) methods. Similar results were obtained with both types of analyses.

For all genes, qPCR efficiencies, detection limits, and dynamic ranges were assessed by mean of fourfold serial dilutions of pooled cDNA (five standards assayed in triplicate: 1:1, 1:4, 1:16, 1:64, and 1:256). Serially diluted cDNAs were used to construct standard curves and estimates of efficiencies, slope of the curves and the correlation coefficient (supplemental Table 2, available at www.jneurosci.org as supplemental material).

Given that there is no reason to expect a single gene to be the most stably expressed EndG in all samples, the reliability of one or more reference genes was determined before proceeding with quantitative mRNA expression studies. Twelve samples (six samples of WT and six samples of $\mathrm{mib}^{\text {hi904 }}$ ) were used to verify expression stability of four different commonly used EndGs (Tang et al., 2007; Chen et al., 2008; Lin et al., 2009): small subunit ribosomal RNA (18S), protein elongation factor $1 \alpha$ subunit (EF1 $\alpha), \beta$-actin ( $\beta$-act), and $\beta-2$ microglobulin $(\beta 2 \mathrm{M})$. Bestkeeper Excel-based tool (Pfaffl et al., 2004) and NormFinder (Andersen et al., 2004) software were used to rank all the EndGs. Bestkeeper assesses candidate genes by pairwise correlations based on CT values that are then combined into an index and calculates the SD of the CT values between the whole dataset. NormFinder uses a model-based approach to rank all reference gene candidates based on intergroup and intragroup expression variations. Analyzed with both programs (BestKeeper and NormFinder), the $\beta$-act gene was the most stable gene, followed by $\mathrm{EF} 1 \alpha, \beta 2 \mathrm{M}$, and $18 \mathrm{~S}$ (data not shown); $\beta$-act was used in our studies for data normalization.

Student's $t$ test was used to determine statistical significance between the normalized relative expression values in $\mathrm{qPCR}$ assay. $p \leq 0.05$ was considered to be significant.

\section{Results}

\section{Electrographic seizures in mind bomb mutant zebrafish}

Brain malformations resulting from errors in neurodevelopment are commonly associated with significant cognitive delay, autism, and intractable epilepsy (Schwartzkroin and Walsh, 2000; Guerrini and Marini, 2006). To identify zebrafish with a brain malformation and epilepsy, a brief "shelf screen" of previously identified mutants with grossly visible brain abnormalities was performed. Adult zebrafish mutant lines ( mib ${ }^{\text {hi } 904} ; \mathrm{mib}^{\text {ta52b}}$; tcp ${ }^{\text {hi3564 }}$; hdac ${ }^{\text {hi1618 }}$; $d t l^{\text {hi447 }}$ ) were obtained from the Zebrafish International Resource Center. Offspring from these mutants were sorted at 2 or $3 \mathrm{dpf}$ based on morphology, e.g., small or misshapen head, smaller eyes, and, in many cases, a dorsally curled body. Representative WT sibling and $m i b^{h i 904}$ zebrafish larvae at $3 \mathrm{dpf}$ are shown in Figure 1, $A 1$ and B1. Field recordings were obtained from forebrain or optic tectum for recording periods up to $1 \mathrm{~h}$. Recurrent spontaneous multispike bursts $>1000$ $\mathrm{ms}$ in duration were observed in $93 \%$ of mib $^{\text {hi }}{ }^{204}$ mutants $(n=$ 28 ) at frequencies between 0.2 and 1.5 bursts/min (Fig. 1B2,C). Analysis of burst duration (control, $0.17 \pm 0.07 \mathrm{~s} ; \mathrm{mib}, 3.3 \pm 0.91 \mathrm{~s}$; Student's $t$ test, $p=0.003$ ) and frequency (control, $0.05 \pm 0.01$ bursts/min; mib, $0.8 \pm 0.14$ bursts/min; Student's $t$ test, $p=0.0001$ ) confirmed that these differences were significant. Prolonged burst discharges were similar in waveform to those classified as "ictal-like" after exposure to $15 \mathrm{~mm}$ pentylenetetrazole (PTZ), a GABA receptor antagonist (Fig. 1C) (Baraban et al., 2005). Only brief and infrequent field bursts were observed in age-matched WT siblings (Fig. 1A2,C) $(n=18)$. Tectal field response to paired-pulse stimulation of the contralateral eye was comparable between $\mathrm{mib}^{\text {hi904 }}$ and control fish (compare traces in Fig. 1D). Analysis of paired-pulse data at $20 \mathrm{~s}$
A
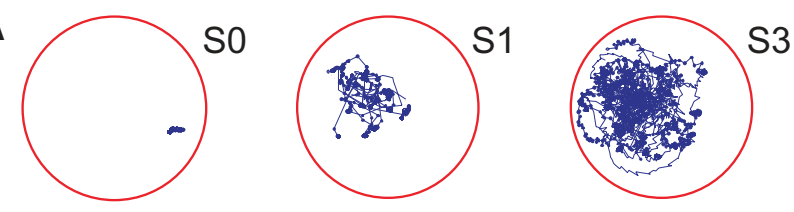

B

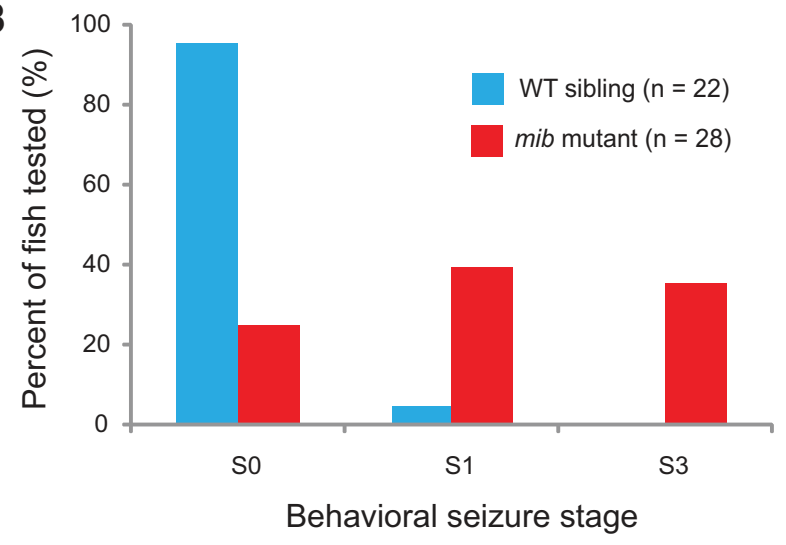

Figure 2. Seizure behaviors in immature mind bomb zebrafish. $A$, Sample locomotion tracking plots are shown for mib ${ }^{\text {hig04 }}$ mutant zebrafish in normal bathing medium. Blue dots indicate movement; lines indicate rapid convulsive-like activity. Plots are shown for typical stage 0 (SO; no swim activity), stage 1 (S1; increased swim activity), and stage 3 (S3; full-body convulsions) recording epochs. For an example of a stage 3 seizure, see supplemental Video 1 (available at www.jneurosci.org as supplemental material). $\boldsymbol{B}$, Bar plot showing the percentage of all fish recorded during locomotion tracking. Plots were scored by individuals blind to the status of the zebrafish and show a clear trend toward spontaneous seizure-like behavior in mib ${ }^{\text {hig04 }}$ mutant zebrafish.

Table 2. Global repartition of the $n=150$ (annotated) differentially expressed genes between mib and WT zebrafish ( $n=3$ pools of 10 fish per pool)

\begin{tabular}{llll}
\hline $\begin{array}{l}\text { Pathways and biological } \\
\text { function }\end{array}$ & $\begin{array}{l}\text { Differentially expressed } \\
\text { genes (\%) }\end{array}$ & $\begin{array}{l}\text { Upregulated } \\
\text { genes }\end{array}$ & $\begin{array}{l}\text { Downregulated } \\
\text { genes }\end{array}$ \\
\hline Cellular process & $103(68.7 \%)$ & 47 & 56 \\
$\quad$ Signal transduction & 37 & 20 & 17 \\
$\quad$ Transcription & 23 & 8 & 15 \\
$\quad$ Cellular metabolic process & 31 & 12 & 19 \\
$\quad$ Other cellular process & 12 & 7 & 5 \\
Development & $25(16.7 \%)$ & 10 & 15 \\
Transport & $13(8.7 \%)$ & 3 & 10 \\
Immune response/response & $9(6 \%)$ & 5 & 4 \\
$\quad$ to stimulus & & &
\end{tabular}

Global repartition of the 150 (annotated) differentially expressed genes between mib ${ }^{\text {hig04 }}$ and WT zebrafish ( $n=3$ pools of 10 fish per pool). These data were extracted after statistical analysis of microarrays for detection of differentially expressed genes and then from gene ontology analysis for clustering differentially expressed genes by function.

interpulse intervals did not reveal significant differences in facilitation (control, $107 \pm 14 \%$; mib, $106 \pm 9 \%$; Student's $t$ test, $p=0.94$ ). Abnormal electrical discharge was not observed in gap-free recordings from $t c p^{h i 3564}$ mutants between 3 and $6 \mathrm{dpf}(n=$ 12) or $h d a c^{h i 1618}$ mutants at $3 \mathrm{dpf}(n=3)$. Identifiable offspring from $m i b^{t a 52 b}$ or $d t l^{h i 447}$ mutants were not viable beyond $2 \mathrm{dpf}$.

\section{Behavioral seizure activity in mind bomb mutant zebrafish}

Behavioral manifestations of electrographic seizures include episodes of excessive locomotor activity and myoclonus of all four limbs and are well characterized in rodent models of epilepsy (Pitkänen et al., 2006). To further characterize epilepsy in mib ${ }^{\text {hi904 }}$ mutant zebrafish larvae, offspring were placed in one well of a 96-well Falcon plate, and the behavior of freely swimming fish 
was observed under a stereomicroscope. Using a scoring system developed for acute seizures (Baraban et al., 2005), a CCD camera, and locomotion tracking software, $10 \mathrm{~min}$ recording epochs were obtained for mib ${ }^{\text {higo4 }}(n=28)$ and agematched WT siblings $(n=22)$ bathed in normal embryo media at $3 \mathrm{dpf}$. Behaviors consistent with stage I [increased swim activity (Fig. 2A)] and stage 3 [brief and violent clonus-like convulsions (Fig. 2A)] were consistently noted in mib $\mathrm{mig04}^{\text {mu- }}$ tants (Fig. $2 B$ ). WT zebrafish were primarily observed to exhibit behaviors that could be characterized as stage 0 (little or no swim activity) (Fig. $2 \mathrm{~B}$ ). Analysis of the percentage of time moved during $10 \mathrm{~min}$ epochs scored as stage 3 (mib, $0.12 \pm$ $0.05 \% ; n=8$ ) or stage 0 (control, $0.0 \pm$ $0.0 \% ; n=11$ ) confirmed that these differences were significant (Student's $t$ test, $p=0.015)$. Video of a representative stage 3 seizure event in an mib migo4 $^{\text {mutant is }}$ shown in supplemental Video 1 (available at www.jneurosci.org as supplemental material). Electrographic seizures were confirmed in a subset of mib ${ }^{\text {hi904 }} \mathrm{mu}$ tants that were first monitored for behavioral seizure activity and then embedded in agar for electrophysiological recording $(n=4)$.

\section{Microarray analysis and gene categorization}

To identify potential signaling pathways and transcriptional activation patterns that could give insight into the epileptic phenotype observed in $\mathrm{mib}^{\text {hig04 }}$ mutants, we performed transcriptome analysis using an Affymetrix zebrafish microarray. Hierarchical clustering analysis showed that $\sim 1.9 \%$ (247 genes) of the genes $( \pm 13,151$ array probes selected after elimination of controls and blank) (supplemental Fig. 2, available at www.jneurosci.org as supplemental material) were differentially expressed between wild-type sibling and mib ${ }^{h i 904}$ mutants ( $p \leq 0.05$, $t$ test; GeneSpring GX 7.3.1); 97 genes were assigned to an "unknown function" category and not analyzed further. Among the 150 genes differentially expressed between these two groups, a similar amount of genes exhibited higher ( $n=65 ; 43 \%$ upregulated) (supplemental Table 3, available at www.jneurosci.org as supplemental material) and lower ( $n=85 ; 57 \%$ downregulated) (supplemental Table 4, available at www.jneurosci.org as supplemental material) expression in $\mathrm{mib}^{\text {hig04 }}$. Based on literature searches, these genes were grouped into four broad categories: cellular process $(n=103)$, development $(n=25)$, transport $(n=13)$, and immune response/response to a stimulus $(n=9)$ (Table 2) (supplemental Fig. 3, available at www. jneurosci.org as supplemental material).

As shown in Table 2, many of the genes in the "cellular process" category pertain to signal transduction, transcription, and general (cellular) metabolic process; additional genes were involved in other cellular process, such as apoptosis, cell adhesion, etc. Several gene products in our microarray screen correspond to Danio rerio homologs of previously identified activity-regulated transcripts found in mammals after seizure (Flood et al., 2004; Gorter et al., 2006), including the immediate early gene Fos, the CCAAT element
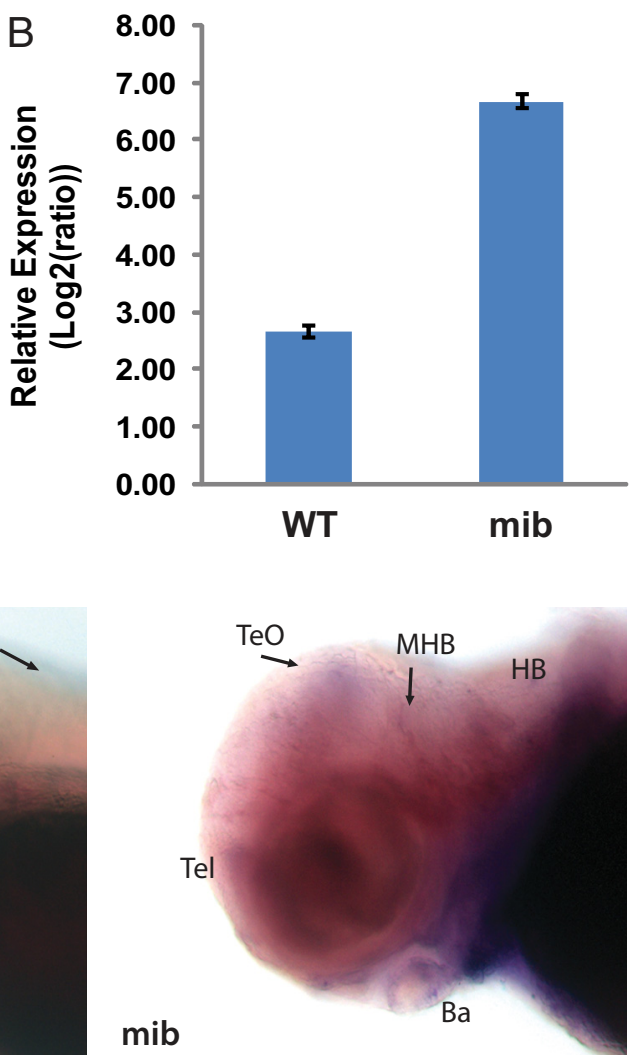

mib

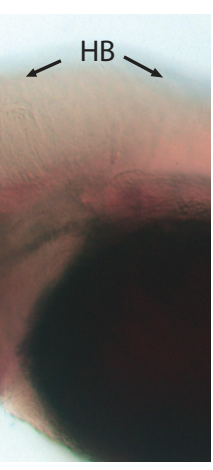

Figure 3. Expression pattern of BDNF in WT and mib ${ }^{\text {hig04 }}$ zebrafish ( $3 \mathrm{dpf}$ ). $\boldsymbol{A}$, Detection of gene expression in $2 \%$ ethidium upregulation in the telencephalon, optic tectum, midbrain, and hindbrain of age-matched mib ${ }^{\text {hig04 }}$ mutants. Ba, Branchial arches; $D C$, diencephalon; $\mathrm{HB}$, hindbrain; $\mathrm{MHB}$, midbrain hindbrain boundary; Tel, telencephalon; Te0, optic tectum.

binding protein encoded by $c / E B P$, early growth response 1 , and brain-derived neurotrophic factor (BDNF). As a general category with putative roles in the generation of abnormal electrical activity a number of gene products related to inhibitory synaptic transmission were noted as downregulated, e.g., glutamate decarboxylase 1 (GAD1), similar to GABA transporter 1, glycine receptor $\alpha 4 \mathrm{~b}$, calbindin 2 (Calb2), and parvalbumin isoform $2 \mathrm{a}$ (Pvalb5).

To validate the microarray results, we analyzed a subset of genes using three independent methods for evaluating RNA expression: (1) conventional RT-PCR, (2) qPCR, and (3) WISH. For all seven transcripts assayed, RT-PCR detection of gene expression levels were confirmed in a qualitative manner, and the average fold change in gene expression reported in the microarray data was statistically confirmed by qPCR. Spatial expression patterns for the selected genes assessed using WISH were consistent with PCR findings. In the following sections, several of these genes are discussed in more detail.

\section{Upregulation of seizure-related gene transcripts in mind bomb mutant zebrafish}

Seizure-induced expression of activity-dependent CNS genes has been described in animal models and tissue obtained at surgery from patients with intractable forms of epilepsy (Hendriksen et al., 2001; Elliott et al., 2003; Hunsberger et al., 2005; Rakhade et al., 2005; Xi et al., 2009). One of these previously described genes, BDNF, a member of the "neurotrophin" family of growth factors, is believed to play a role in synaptic plasticity and excitability (Croll et al., 1999; Cowansage et al., 2010). In agreement with previous reports, BDNF expression is increased nearly threefold in $m i b^{h i 904}$ mutants (Fig. 3B). 
A
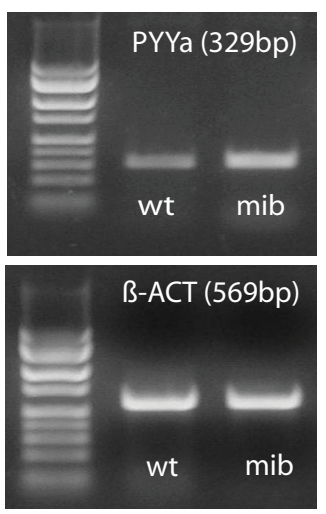

C

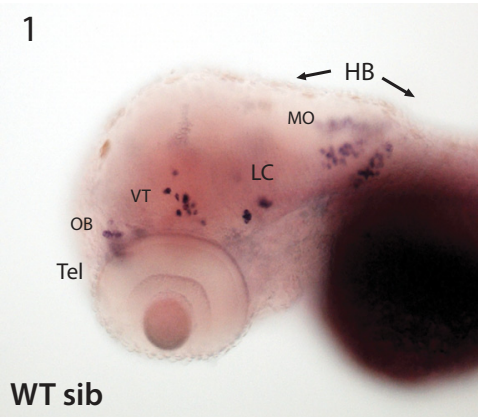

2

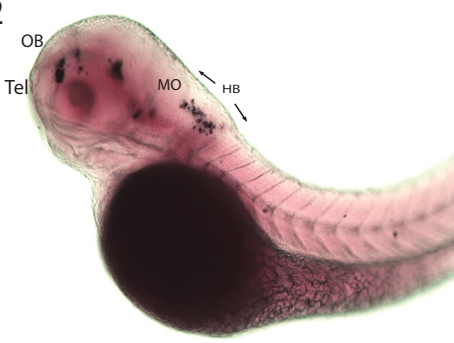

WT sib

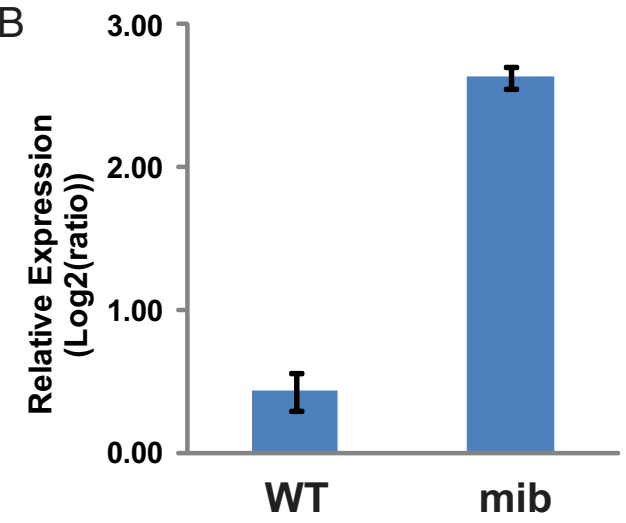

3

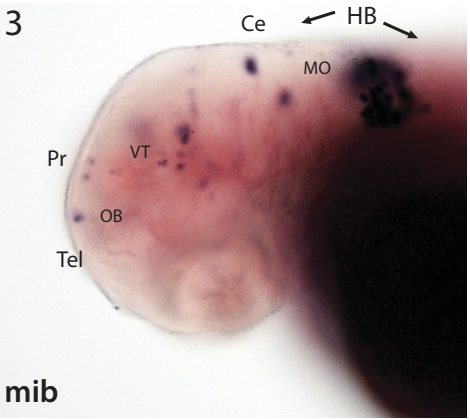

4

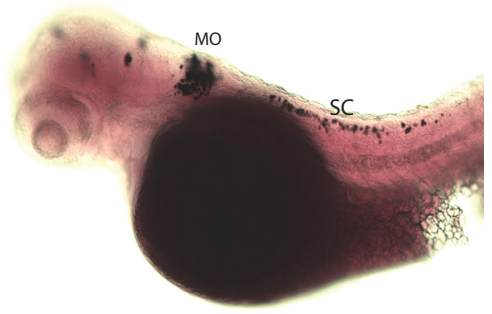

mib

Figure 4. Expression pattern of PYYa in WT and mib ${ }^{\text {hig04 }}$ zebrafish (3 dpf). $A$, Detection of gene expression in $2 \%$ ethidium bromide agarose gel electrophoresis. $\boldsymbol{B}$, Levels of mRNA, measured by quantitative PCR and normalized to $\beta$-act. Error bars indicate $\pm \mathrm{SEM}$. Student's $t$ test, $p<0.05$. C, Whole-mount in situ hybridization, lateral view. Note a low-level expression of PYYa near the olfactory bulb, locus ceruleus, ventral thalamic cluster, and hindbrain in wild-type sibling zebrafish and a prominent upregulation of gene expression in hindbrain extending into the spinal cord in mib ${ }^{\text {higot }}$ mutants. Ce, Cerebellum; $\mathrm{LC}$, locus ceruleus; $\mathrm{HB}$, hindbrain; $\mathrm{MO}$, medulla oblongata; $\mathrm{OB}$, olfactory bulb; Pr, pretectum; SC, spinal cord; Te0, optic tectum; Tel, telencephalon; VT, ventral thalamic cluster.

In contrast to the low level of endogenous CNS expression of BDNF in WT sibling zebrafish, a diffuse but prominent upregulation was observed in the telencephalon, optic tectum, midbrain, and hindbrain of age-matched mib ${ }^{\text {higo4 }}$ mutants (Fig. 3C). Another previously described gene, peptide YYa (PYYa), a member of the neuropeptide $Y$ family thought to act as an endogenous anticonvulsant (Baraban et al., 1997; Vezzani et al., 1999), exhibits a nearly threefold increase in mib ${ }^{\text {hi904 }}$ mutants (Fig. 4B). In WT sibling zebrafish, PYYa is expressed at a relatively low level near the olfactory bulb (OB), locus ceruleus (LC), ventral thalamic cluster, and hindbrain (Fig. 4C1,C2). In mib ${ }^{\text {hi904 }}$ mutants, we observed a slight reduction of PYYa expression near the $\mathrm{OB}$ and LC but prominent upregulation of gene expression in hindbrain (Fig. 4C3) extending into spinal cord (Fig. 4C4).

\section{Downregulation of GABA-related} gene transcripts in mind bomb mutant zebrafish

Reduction in expression of genes related to GABAergic signaling has been commonly described in the epilepsy, autism, and schizophre- nia literature (Harrison and Weinberger, 2005; Akbarian and Huang, 2006; BrooksKayal et al., 2009). As a general marker of GABA-mediated synaptic function, GAD1, an enzyme responsible for catalyzing the production of GABA from L-glutamic acid, was reduced by nearly $75 \%$ in $\mathrm{mib}^{\text {hi904 }}$ mutants (Fig. 5B). This dramatic reduction was most prominent in a ventral view of the zebrafish head showing a near absence of GAD1 expression in the boundary of the olfactory pit and diencephalon (Fig. 5C), a region in which GABAergic interneurons are thought to originate (Mione et al., 2008). Interestingly, GAD1 expression was also found to be decreased by microarray and real-time qPCR analysis of $m i b^{t a 52 b}$ mutants (Hegde et al., 2008). We also analyzed the Danio rerio homolog for the $\alpha 1$ subunit of the $\mathrm{GABA}_{\mathrm{A}}$ receptor (Fig. 6), as a complimentary gene associated with postsynaptic GABA-mediated signaling and a subunit associated with an autosomal dominant form of juvenile myoclonic epilepsy (Krampfl et al., 2005) but not included on the Affymetrix gene array. This subunit was shown to be downregulated nearly twofold in qPCR analysis of $\mathrm{mi}$ $b^{\text {hi904 }}$ mutants (Fig. 6 B). Interestingly, the spatial expression patterns in WISH showed a dramatic reduction in $\mathrm{GABA}_{\mathrm{A}}$ receptor, $\alpha 1$ (Gabra1) expression in the telencephalon, optic tectum, and hindbrain (Fig. 6C). In addition, the $\alpha 4$ glycine receptor subunit, a signaling pathway mediating inhibitory neurotransmission in the spinal cord and brainstem (Yoshimura and Nishi, 1982; Legendre, 2001), was also found to be downregulated in mib ${ }^{\text {hi904 }}$ mutants (supplemental Fig. 4, available at www.jneurosci.org as supplemental material).

Calcium-binding proteins are widely used as expression markers for specific interneuron subtypes (Xu et al., 2004; Batista-Brito et al., 2008). Our data show a significant reduction of two of these markers in mib ${ }^{\text {hi } 904}$ mutants: calbindin (Fig. 7) and parvalbumin (Fig. 8). Quantitative PCR analysis reveals a $>50 \%$ reduction in expression for both gene products (Figs. $7 B, 8 B$ ). Calbindin shows a diffuse CNS expression pattern in the telencephalon, optic tectum, cerebellum, and hindbrain that is dramatically reduced in mib $^{\text {hi904 }}$ mutants (Fig. 7C). Parvalbumin, a marker of fast-spiking basket-type interneurons (Cauli et al., 1997), expression in a restricted region of the telencephalon and hypothalamus showed a clear reduction with a more diffuse decrease in expression across the entire brain (Fig. 8C).

\section{Discussion}

E3 ubiquitin ligases have been linked to the control of many cellular processes and to multiple human diseases. Here, we present data suggesting that a mind bomb mutant deficient in E3 ubiquitin ligase activity exhibits epilepsy that may be associated with reduced GABA-mediated signaling. Decreased GABAergic 
signaling is among the more robust pathologies observed postmortem in schizophrenia, autism, and epilepsy (van Kammen et al., 1998; Thom et al., 2004; Akbarian and Huang, 2006; Fatemi et al., 2009; Mellios et al., 2009; Lawrence et al., 2010). The phenotype of immature mi$b^{\text {hi904 }}$ zebrafish suggests that this mutant may facilitate a mechanistic analysis of the pathogenesis of E3 ubiquitin ligaserelated diseases and provide a model system to search for more effective treatments.

\section{Spontaneous seizures in the mind bomb mutant}

The "neurogenic" phenotype in zebrafish mind bomb mutants is associated with defects in neural patterning and brain development (Jiang et al., 1996; Bingham et al., 2003). Because developmental brain abnormalities are recognized as an important feature of intractable childhood seizure disorders (Schwartzkroin and Walsh, 2000), we were initially interested in determining whether immature zebrafish mutants with grossly abnormal brain structure exhibit spontaneous seizure activity resembling that seen in 3 and 7 dpf zebrafish exposed to convulsant drugs (Baraban et al., 2005, 2007). Using mutants identified in chemical mutagenesis screens, epileptiform-like discharges were only observed in mib ${ }^{\text {hi904 }}$ zebrafish. Although neuronal correlates of these recurrent burst discharges are not yet known, the waveforms can be considered an "EEG-like" representation of seizure activity because they appear in CNS structures and are consistent with clinical criteria used to define epilepsy (Engel, 2006). At $3 \mathrm{dpf}$, wild-type zebrafish rarely move. However, intermittent spasms of convulsive behavior were consistently observed in age-matched mib ${ }^{h i 904}$ mutants. Compared with previous locomotion monitoring in PTZ-exposed zebrafish and with appropriate caution, we can attempt to quantify these behaviors as stage 3 "seizures." Obviously, human and rodent seizure behavior differs qualitatively and quantitatively from that observed in zebrafish. Nonetheless, these behaviors have never been reported in undisturbed WT zebrafish, and, together with the electrophysiological data, suggest a novel epileptic phenotype.

Acute zebrafish seizures, induced by exposure to PTZ, show many similarities to chemoconvulsant-induced events in rodents: progressive stages of behavior; complex electrographic discharges; induction of immediate early gene expression; prolonged waves of neuroluminescence; and similar profiles of antiepileptic drug responsiveness (Baraban et al., 2005; Berghmans et al., 2007; Naumann et al., 2010). In Drosophila, physiological correlates of behavioral seizure-like events can be observed after electroconvulsive stimulation (Kuebler and Tanouye, 2000; Lee and Wu, 2002) and in Caenorhabditis elegans (Williams et al., 2004) or Xenopus laevis (Hewapathirane et al., 2008) with exposure to chemoconvulsant drugs. These model organisms, although ideally suited for analysis of seizure propagation and molecular mechanisms involved in seizure generation, do not represent models of epilepsy defined as the occurrence of unprovoked recurrent seizures. In contrast, in telencephalic and tectal recordings from immobilized $\mathrm{mib}^{\text {hi }}{ }^{\mathrm{m}} \mathrm{mu}$ tant zebrafish, spontaneously occurring epileptiform discharges were observed in the absence of external stimuli.

How is it possible to generate epileptic activity in immature zebrafish? A simple answer is that the zebrafish brain possesses critical functional capacities thought to be necessary for generation of epileptic events in any species. Notably, excitatory neurotransmission mediated by three ionotropic glutamate receptor subtypes (Edwards and Michel, 2003) and inhibitory interneurons exerting actions via activation of postsynaptic $\mathrm{GABA}_{\mathrm{A}}$ receptors (Sajovic and Levinthal, 1983; C. H. Kim et al., 1996; Y. J. Kim et al., 2004). These basic excitatory and synaptic components serve complex CNS computations in zebrafish, such as "secondorder motion perception” (Orger et al., 2000), long-term potentiation (Nam et al., 2004), or odor-evoked neural coding (Edwards and Michel, 2002; Mack-Bucher et al., 2007), and could be responsible for generation of abnormal electrical discharge.

\section{Relevant differential gene expression patterns in the mind bomb mutant}

Because one of the primary uses of an experimental model is to simplify a complex situation, we proceeded with a transcriptome analysis of mib ${ }^{h i 904}$ zebrafish. In considering potential interpretations of these data, it is important to consider a few caveats. First, zebrafish, although possessing distinct advantages as a "simple" vertebrate species, are considered to have a less complex CNS with no clear homology for some mammalian structures thought to be important for seizure generation, i.e., hippocampus and septum. The CNS of most vertebrates develops from a folding mechanism in which the lateral edges of the neural 
A
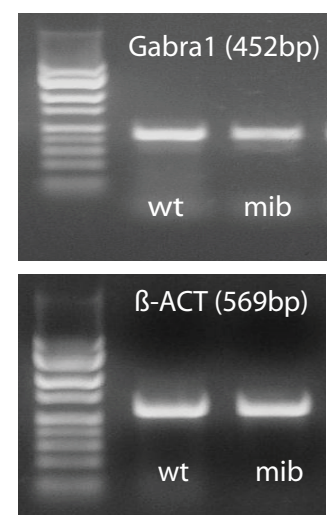

B

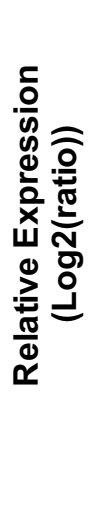

C

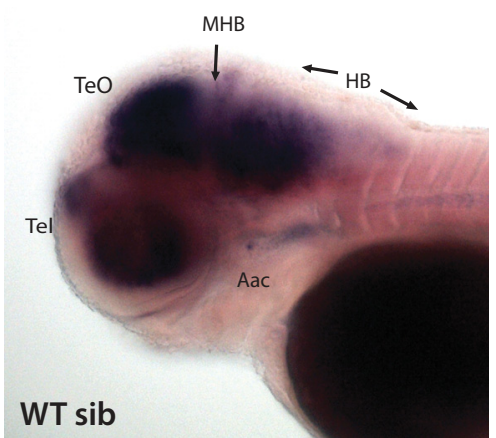

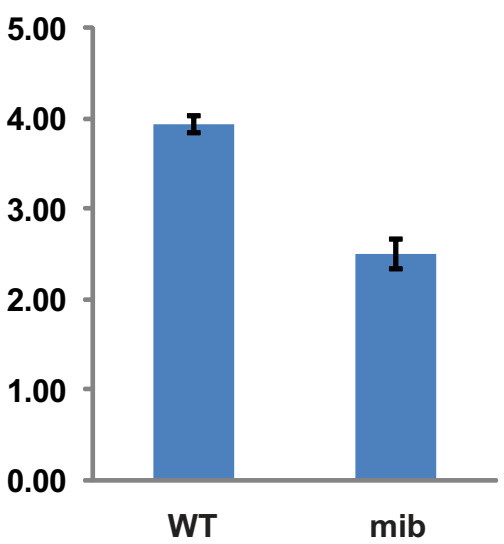

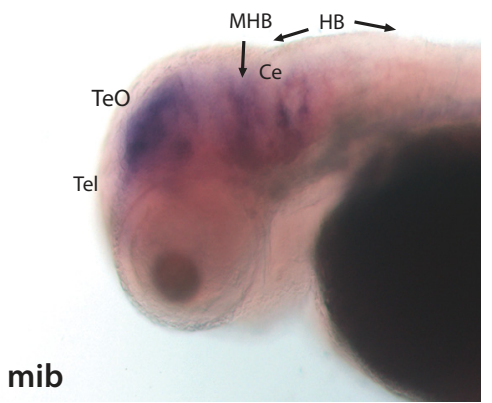

Figure 6. Expression pattern of Gabra1 in WT and mib ${ }^{\text {hig04 }}$ zebrafish ( $3 \mathrm{dpf}$ ). $A$, Detection of gene expression in $2 \%$ ethidium bromide agarose gel electrophoresis. $\boldsymbol{B}$, Levels of mRNA, measured by quantitative PCR and normalized to $\beta$-act. Error bars indicate \pm SEM. Student's $t$ test, $p<0.05$. C, Whole-mount in situ hybridization, lateral view. Note a dramatic reduction in the spatial expression pattern of Gabra1 in mib ${ }^{\text {hig04 }}$ mutants in the telencephalon, optic tectum, and hindbrain. Aac, Arch associated cells; Ce, cerebellus; HB, hindbrain; MHB, midbrain hindbrain boundary; Te0, optic tectum; Tel, telencephalon.

plate come together and fuse at the dorsal midline. However, the zebrafish neural plate is initially a solid structure that then develops a central canal by detachment of cells in the center (Blader and Strähle, 2000). Although everted in its final form, the general organization of telencephalic hemispheres and optic tectum in zebrafish suggest that these regions receive multimodal input from a variety of sources and share many organizational similarities with higher species (Vanegas and Ebbesson, 1976; Murakami et al., 1983; Ekström et al., 1986; Wullimann et al., 1996; Guo et al., 1999). Second, our analysis, using a single microarray, is limited by detection biases. Although we could identify transcripts in the GABA signaling pathway, the microarray is not sensitive to low abundance transcripts or those with restricted expression patterns. Moreover, this approach is not comprehensive in that many gene products involved in regulating excitability-ion channel variants and receptor subunits-are not represented on the microarray.

Microarrays have been used extensively to identify molecular processes that may underlie acute or chronic seizure activity (Hendriksen et al., 2001; Elliott et al., 2003; Hunsberger et al., 2005; Rakhade et al., 2005; Xi et al., 2009). In the epileptic brain, upregulation of numerous genes mediating cell injury or survival is expected given the well known damage that can occur with excessive electrical activity (Sloviter, 1996; Houser, 1999; Elliott et al., 2001). Although the large percentage of cellular process genes identified as differentially expressed in $m_{i b} b^{h i 904}$ mutants fit with known cellular demands associated with seizure activity, it is also possible that these findings reflect the higher representation of gene transcripts related to metabolism, immune response, and injury on the microarray. Interestingly, upregulation of activity-dependent genes with well established roles in the epileptogenic process validate our zebrafish model and further suggest a set of "commonality genes" that are upregulated in a variety of species, including human, after seizure. Moreover, this list is not confined to the two genes confirmed here in a series of RNA expression studies (e.g., BDNF and PYY) but could be expanded to include transcripts identified in three or more independent epilepsy-related microarray studies [e.g., chemokine (C-X-F motif) ligand, protein kinase $\mathrm{C}$, ornithine decarboxylase, early growth response 1, fibronectin, and cathepsins]. Additional analysis of these transcripts in mib $^{\text {higo4 }}$ mutants and, perhaps, manipulation of these same genes in wild-type zebrafish using morpholino antisense oligonucleotides (Ekker, 2000) or Tol2-mediated transgenesis (Halpern et al., 2008) could help define roles in epileptogenesis.

Although our analysis did not focus on differential expression of gene transcripts related to Notch signaling and neurodevelopment, this is an important area for future investigation. In particular, CNS expression patterns for hairy-related genes (her4, her5, her6, her8a, her9, and hes5) and proneural factors (asc1b, atoh $2 a, n g n 1$, and neurod) identified as downregulated in three different microarray analyses of mib mutants (Table 2) (Hegde et al., 2008; Hwang et al., 2009) warrant additional analysis. Grossly abnormal development and early fatality suggest important roles for these genes in establishing the mind bomb phenotype.

\section{Potential relevance to human neurological disease}

Missense mutant alleles of human ubiquitin E3A ligase that result in loss of function have been identified in Angelman syndrome (Kishino et al., 1997; Matsuura et al., 1997; Camprubí et al., 2009), and loss-of-function point mutations have been reported in patients with autism spectrum disorder (Muhle et al., 2004). One potential model for these neurological symptoms posits that, in the absence of ubiquitin ligase activity, one or more ubiquitin ligase substrates accumulate in the brain and interfere with CNS development and/or function. Drosophila E3 ubiquitin ligase mutants ( $d U B E 3 A$ ) were used recently to test this hypothesis: (1) Wu et al. (2008) demonstrated that $d U B E 3 A$ deletion mutants display a loss of motor coordination and cognitive impairment on olfaction and shock test paradigms that could be rescued by transgene expression, and (2) Lu et al. (2009), also using $d U B E 3 A$-null mutant flies, reported deficits in the dendritic branching of sensory neurons. Although electroconvulsive stimulation can be used to assess seizure thresholds in fruit flies (Kuebler and Tanouye, 2000), these studies were not performed. Null mutation of Ube3a in mice (Jiang et al., 1998; Miura et al., 2002) results in impairment of hippocampal long-term potentiation (an in vitro correlate of learning and memory), increased susceptibility to induced seizures, and intermittent bursts of spike-wave discharges in some animals. Although the precise nature of this disorder re- 
mains to be determined, there is a growing body of literature, supported here in our analysis of a zebrafish E3 ubiquitin ligase mutant, suggesting that dysfunction of GABA-mediated inhibitory neurotransmission is a key factor in the pathophysiology.

\section{References}

Akbarian S, Huang HS (2006) Molecular and cellular mechanisms of altered GAD1/GAD67 expression in schizophrenia and related disorders. Brain Res Rev 52:293-304.

Andersen CL, Jensen JL, Ørntoft TF (2004) Normalization of real-time quantitative reverse transcription-PCR data: a model-based variance estimation approach to identify genes suited for normalization, applied to bladder and colon cancer data sets. Cancer Res 64:5245-5250.

Baraban SC, Hollopeter G, Erickson JC, Schwartzkroin PA, Palmiter RD (1997) Knock-out mice reveal a critical antiepileptic role for neuropeptide Y. J Neurosci 17:8927-8936.

Baraban SC, Taylor MR, Castro PA, Baier H (2005) Pentylenetetrazole induced changes in zebrafish behavior, neural activity and c-fos expression. Neuroscience 131:759-768.

Baraban SC, Dinday MT, Castro PA, Chege S, Guyenet S, Taylor MR (2007) A large-scale mutagenesis screen to identify seizureresistant zebrafish. Epilepsia 48:1151-1157.

Batista-Brito R, Machold R, Klein C, Fishell G (2008) Gene expression in cortical interneuron precursors is prescient of their mature function. Cereb Cortex 18:2306-2317.

Berghmans S, Hunt J, Roach A, Goldsmith P (2007) Zebrafish offer the potential for a primary screen to identify a wide variety of potential anticonvulsants. Epilepsy Res 75:18-28.

Bingham S, Chaudhari S, Vanderlaan G, Itoh M, Chitnis A, Chandrasekhar A (2003) Neurogenic phenotype of mind bomb mutants leads to severe patterning defects in the zebrafish hindbrain. Dev Dyn 228:451-463.

Blader P, Strähle U (2000) Zebrafish developmental genetics and central nervous system development. Hum Mol Genet 9:945-951.

Brooks-Kayal AR, Raol YH, Russek SJ (2009) Alteration of epileptogenesis genes. Neurotherapeutics 6:312-318.

Camprubí C, Guitart M, Gabau E, Coll MD, Villatoro S, Oltra S, Roselló M, Ferrer I, Monfort S, Orellana C, Martínez F (2009) Novel UBE3A mutations causing Angelman syndrome: different parental origin for single nucleotide changes and multiple nucleotide deletions or insertions. Am J Med Genet A 149A:343-348.

Cauli B, Audinat E, Lambolez B, Angulo MC, Ropert N, Tsuzuki K, Hestrin S, Rossier J (1997) Molecular and physiological diversity of cortical nonpyramidal cells. J Neurosci 17:3894-3906.

Chen W, Casey Corliss D (2004) Three modules of zebrafish Mind bomb work cooperatively to promote Delta ubiquitination and endocytosis. Dev Biol 267:361-373.

Chen YC, Kao SC, Chou HC, Lin WH, Wong FH, Chow WY (2008) A real-time PCR method for the quantitative analysis of RNA editing at specific sites. Anal Biochem 375:46-52.

Chitnis A, Henrique D, Lewis J, Ish-Horowicz D, Kintner C (1995) Primary neurogenesis in Xenopus embryos regulated by a homologue of the Drosophila neurogenic gene Delta. Nature 375:761-766.

Clayton-Smith J, Laan L (2003) Angelman syndrome: a review of the clinical and genetic aspects. J Med Genet 40:87-95.

Cowansage KK, LeDoux JE, Monfils MH (2010) Brain-derived neurotrophic factor: a dynamic gatekeeper of neural plasticity. Curr Mol Pharmacol 3:12-29.

Croll SD, Chesnutt CR, Greene NA, Lindsay RM, Wiegand SJ (1999) Peptide immunoreactivity in aged rat cortex and hippocampus as a function of memory and BDNF infusion. Pharmacol Biochem Behav 64:625-635. de la Pompa JL, Wakeham A, Correia KM, Samper E, Brown S, Aguilera RJ, Nakano T, Honjo T, Mak TW, Rossant J, Conlon RA (1997) Conservation of the Notch signalling pathway in mammalian neurogenesis. Development 124:1139-1148.

Deshaies RJ, Joazeiro CA (2009) RING domain E3 ubiquitin ligases. Annu Rev Biochem 78:399-434.

Edwards JG, Michel WC (2002) Odor-stimulated glutamatergic neurotransmission in the zebrafish olfactory bulb. J Comp Neurol 454:294-309.

Edwards JG, Michel WC (2003) Pharmacological characterization of ionotropic glutamate receptors in the zebrafish olfactory bulb. Neuroscience 122:1037-1047.

Ekker SC (2000) Morphants: a new systematic vertebrate functional genomics approach. Yeast 17:302-306.

Ekström P, Reschke M, Steinbusch H, van Veen T (1986) Distribution of noradrenaline in the brain of the teleost Gasterosteus aculeatus L.: an immunohistochemical analysis. J Comp Neurol 254:297-313.

Elliott RC, Khademi S, Pleasure SJ, Parent JM, Lowenstein DH (2001) Differential regulation of basic helix-loop-helix mRNAs in the dentate gyrus following status epilepticus. Neuroscience 106:79-88.

Elliott RC, Miles MF, Lowenstein DH (2003) Overlapping microarray profiles of dentate gyrus gene expression during development- and epilepsyassociated neurogenesis and axon outgrowth. J Neurosci 23:2218-2227.

Engel J Jr (2006) ILAE classification of epilepsy syndromes. Epilepsy Res 70 [Suppl 1]:S5-S10.

Fatemi SH, Reutiman TJ, Folsom TD, Thuras PD (2009) GABA(A) receptor downregulation in brains of subjects with autism. J Autism Dev Disord 39:223-230.

Flood WD, Moyer RW, Tsykin A, Sutherland GR, Koblar SA (2004) Nxf and Fbxo33: novel seizure-responsive genes in mice. Eur J Neurosci 20:1819-1826

Glessner JT, Wang K, Cai G, Korvatska O, Kim CE, Wood S, Zhang H, Estes A, Brune CW, Bradfield JP, Imielinski M, Frackelton EC, Reichert J, Crawford EL, Munson J, Sleiman PM, Chiavacci R, Annaiah K, Thomas 
A
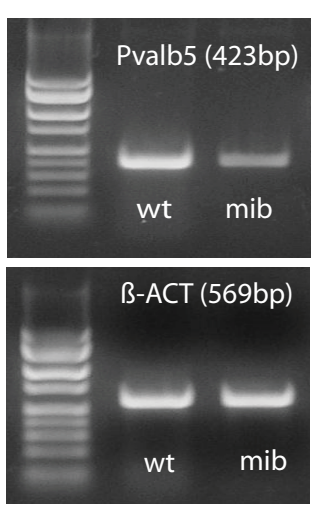

C

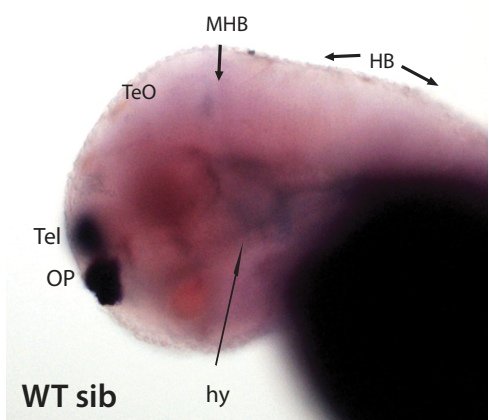

B
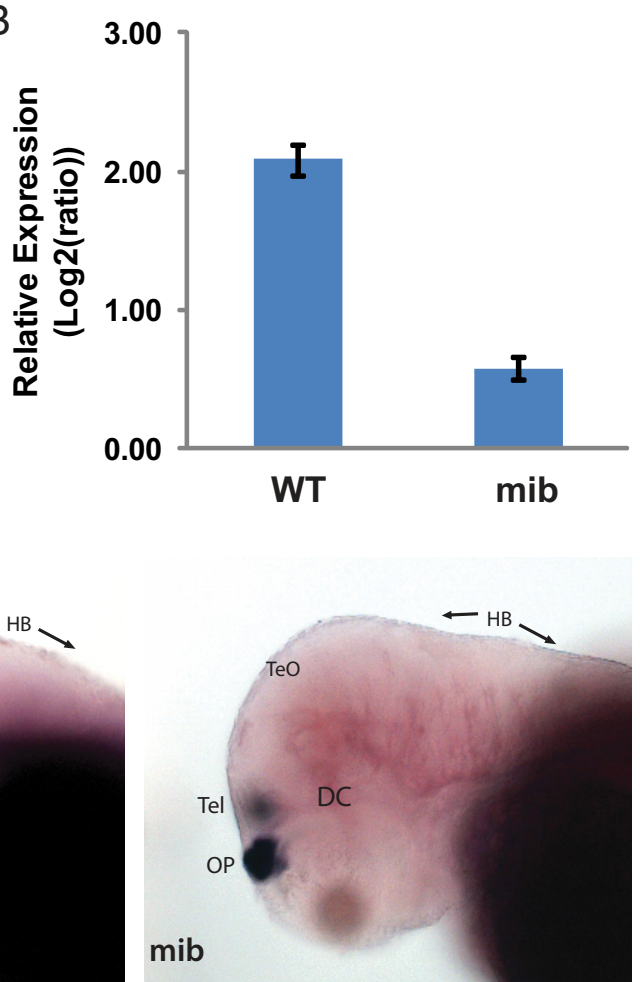

Figure 8. Expression pattern of Pvalb5 in WT and mib ${ }^{\text {hig04 }}$ zebrafish ( $3 \mathrm{dpf}$ ). $\boldsymbol{A}$, Detection of gene expression in $2 \%$ ethidium bromide agarose gel electrophoresis. $\boldsymbol{B}$, Levels of mRNA, measured by quantitative PCR and normalized to $\beta$-act. Error bars indicate \pm SEM. Student's $t$ test, $p<0.05$. C, Whole-mount in situ hybridization, lateral view. Note a clear reduction in Pvalb5 expression across the entire brain in mib ${ }^{\text {hig04 }}$ mutants. DC, Diencephalon; hy, hypothalamus; $\mathrm{HB}$, hindbrain; MHB, midbrain hindbrain boundary; $\mathrm{OP}$, olfactory pits; Tel, telencephalon; Te0, optic tectum.

K, Hou C, et al. (2009) Autism genome-wide copy number variation reveals ubiquitin and neuronal genes. Nature 459:569-573.

Golling G, Amsterdam A, Sun Z, Antonelli M, Maldonado E, Chen W, Burgess S, Haldi M, Artzt K, Farrington S, Lin SY, Nissen RM, Hopkins N (2002) Insertional mutagenesis in zebrafish rapidly identifies genes essential for early vertebrate development. Nat Genet 31:135-140.

Gorter JA, van Vliet EA, Aronica E, Breit T, Rauwerda H, Lopes da Silva FH, Wadman WJ (2006) Potential new antiepileptogenic targets indicated by microarray analysis in a rat model for temporal lobe epilepsy. J Neurosci 26:11083-11110.

Guerrini R, Marini C (2006) Genetic malformations of cortical development. Exp Brain Res 173:322-333.

Guo S, Brush J, Teraoka H, Goddard A, Wilson SW, Mullins MC, Rosenthal A (1999) Development of noradrenergic neurons in the zebrafish hindbrain requires BMP, FGF8, and the homeodomain protein soulless/ Phox2a. Neuron 24:555-566.

Halpern ME, Rhee J, Goll MG, Akitake CM, Parsons M, Leach SD (2008) Gal4/UAS transgenic tools and their application to zebrafish. Zebrafish 5:97-110.

Harrison PJ, Weinberger DR (2005) Schizophrenia genes, gene expression, and neuropathology: on the matter of their convergence. Mol Psychiatry 10:40-68; image 45.

Hauptmann G, Gerster T (1994) Two-color whole-mount in situ hybridization to vertebrate and Drosophila embryos. Trends Genet 10:266.

Hegde A, Qiu NC, Qiu X, Ho SH, Tay KQ, George J, Ng FS, Govindarajan KR, Gong Z, Mathavan S, Jiang YJ (2008) Genomewide expression analysis in zebrafish mind bomb alleles with pancreas defects of different severity identifies putative Notch responsive genes. PLoS One 3:e1479.

Hendriksen H, Datson NA, Ghijsen WE, van Vliet EA, da Silva FH, Gorter JA, Vreugdenhil E (2001) Altered hippocampal gene expression prior to the onset of spontaneous seizures in the rat post-status epilepticus model. Eur J Neurosci 14:1475-1484

Hewapathirane DS, Dunfield D, Yen W, Chen S, Haas K (2008) In vivo imaging of seizure activity in a novel developmental seizure model. Exp Neurol 211:480-488.
Houser CR (1999) Neuronal loss and synaptic reorganization in temporal lobe epilepsy. Adv Neurol 79:743-761.

Hunsberger JG, Bennett AH, Selvanayagam E, Duman RS, Newton SS (2005) Gene profiling the response to kainic acid induced seizures. Brain Res Mol Brain Res 141:95-112.

Hwang J, Kim HS, Seok JW, Kim JD, Koun S, Park SY, Lee J, Kim HS, Kim HS, Kim KS, Chang KT, Ryoo ZY, Wang SM, Huh TL, Lee S (2009) Transcriptome analysis of the zebrafish mind bomb mutant. Mol Genet Genomics 281:77-85.

Itoh $\mathrm{M}$, Kim $\mathrm{CH}$, Palardy $\mathrm{G}$, Oda T, Jiang YJ, Maust D, Yeo SY, Lorick K, Wright GJ, ArizaMcNaughton L, Weissman AM, Lewis J, Chandrasekharappa SC, Chitnis AB (2003) Mind bomb is a ubiquitin ligase that is essential for efficient activation of Notch signaling by Delta. Dev Cell 4:67-82.

Jiang YH, Armstrong D, Albrecht U, Atkins CM, Noebels JL, Eichele G, Sweatt JD, Beaudet AL (1998) Mutation of the Angelman ubiquitin ligase in mice causes increased cytoplasmic p53 and deficits of contextual learning and long-term potentiation. Neuron 21:799-811.

Jiang YJ, Brand M, Heisenberg CP, Beuchle D, Furutani-Seiki M, Kelsh RN, Warga RM, Granato M, Haffter P, Hammerschmidt M, Kane DA, Mullins MC, Odenthal J, van Eeden FJ, Nüsslein-Volhard C (1996) Mutations affecting neurogenesis and brain morphology in the zebrafish, Danio rerio. Development 123:205-216.

Kim CH, Ueshima E, Muraoka O, Tanaka H, Yeo SY, Huh TL, Miki N (1996) Zebrafish elav/ $\mathrm{HuC}$ homologue as a very early neuronal marker. Neurosci Lett 216:109-112.

Kim YJ, Nam RH, Yoo YM, Lee CJ (2004) Identification and functional evidence of GABAergic neurons in parts of the brain of adult zebrafish (Danio rerio). Neurosci Lett 355:29-32.

Kishino T, Lalande M, Wagstaff J (1997) UBE3A/E6-AP mutations cause Angelman syndrome. Nat Genet 15:70-73.

Krampfl K, Maljevic S, Cossette P, Ziegler E, Rouleau GA, Lerche H, Bufler J (2005) Molecular analysis of the A322D mutation in the GABA receptor alpha-subunit causing juvenile myoclonic epilepsy. Eur J Neurosci 22:10-20.

Kuebler D, Tanouye MA (2000) Modifications of seizure susceptibility in Drosophila. J Neurophysiol 83:998-1009.

Lai EC (2002) Protein degradation: four E3s for the notch pathway. Curr Biol 12:R74-R78.

Lawrence YA, Kemper TL, Bauman ML, Blatt GJ (2010) Parvalbumin-, calbindin-, and calretinin-immunoreactive hippocampal interneuron density in autism. Acta Neurol Scand 121:99-108.

Lee J, Wu CF (2002) Electroconvulsive seizure behavior in Drosophila: analysis of the physiological repertoire underlying a stereotyped action pattern in bang-sensitive mutants. J Neurosci 22:11065-11079.

Legendre P (2001) The glycinergic inhibitory synapse. Cell Mol Life Sci 58:760-793.

Lin C, Spikings E, Zhang T, Rawson D (2009) Housekeeping genes for cryopreservation studies on zebrafish embryos and blastomeres. Theriogenology 71:1147-1155.

Livak KJ, Schmittgen TD (2001) Analysis of relative gene expression data using real-time quantitative PCR and the 2(-Delta Delta $\mathrm{C}(\mathrm{T})$ ) method. Methods 25:402-408.

Lu Y, Wang F, Li Y, Ferris J, Lee JA, Gao FB (2009) The Drosophila homologue of the Angelman syndrome ubiquitin ligase regulates the formation of terminal dendritic branches. Hum Mol Genet 18:454-462.

Mack-Bucher JA, Li J, Friedrich RW (2007) Early functional development of interneurons in the zebrafish olfactory bulb. Eur J Neurosci 25:460-470.

Matsuura T, Sutcliffe JS, Fang P, Galjaard RJ, Jiang YH, Benton CS, Rommens JM, Beaudet AL (1997) De novo truncating mutations in E6-AP 
ubiquitin-protein ligase gene (UBE3A) in Angelman syndrome. Nat Genet 15:74-77.

Mellios N, Huang HS, Baker SP, Galdzicka M, Ginns E, Akbarian S (2009) Molecular determinants of dysregulated GABAergic gene expression in the prefrontal cortex of subjects with schizophrenia. Biol Psychiatry 65:1006-1014.

Mione M, Baldessari D, Deflorian G, Nappo G, Santoriello C (2008) How neuronal migration contributes to the morphogenesis of the CNS: insights from the zebrafish. Dev Neurosci 30:65-81.

Miura K, Kishino T, Li E, Webber H, Dikkes P, Holmes GL, Wagstaff J (2002) Neurobehavioral and electroencephalographic abnormalities in Ube3a maternal-deficient mice. Neurobiol Dis 9:149-159.

Muhle R, Trentacoste SV, Rapin I (2004) The genetics of autism. Pediatrics 113:e472-e486.

Murakami T, Morita Y, Ito H (1983) Extrinsic and intrinsic fiber connections of the telencephalon in a teleost, Sebastiscus marmoratus. J Comp Neurol 216:115-131.

Nam RH, Kim W, Lee CJ (2004) NMDA receptor-dependent long-term potentiation in the telencephalon of the zebrafish. Neurosci Lett 370:248-251.

Naumann EA, Kampff AR, Prober DA, Schier AF, Engert F (2010) Monitoring neural activity with bioluminescence during natural behavior. Nat Neurosci 13:513-520.

Orger MB, Smear MC, Anstis SM, Baier H (2000) Perception of Fourier and non-Fourier motion by larval zebrafish. Nat Neurosci 3:1128-1133.

Park HC, Appel B (2003) Delta-Notch signaling regulates oligodendrocyte specification. Development 130:3747-3755.

Pfaffl MW (2001) A new mathematical model for relative quantification in real-time RT-PCR. Nucleic Acids Res 29:e45.

Pfaffl MW, Tichopad A, Prgomet C, Neuvians TP (2004) Determination of stable housekeeping genes, differentially regulated target genes and sample integrity: BestKeeper-Excel-based tool using pair-wise correlations. Biotechnol Lett 26:509-515.

Pitkänen A, Schwartzkroin PA, Moshé SL (2006) Models of seizures and epilepsy. Amsterdam: Elsevier Academic.

Rakhade SN, Yao B, Ahmed S, Asano E, Beaumont TL, Shah AK, Draghici S, Krauss R, Chugani HT, Sood S, Loeb JA (2005) A common pattern of persistent gene activation in human neocortical epileptic foci. Ann Neurol 58:736-747.

Sajovic P, Levinthal C (1983) Inhibitory mechanism in zebrafish optic tectum: visual response properties of tectal cells altered by picrotoxin and bicuculline. Brain Res 271:227-240.

Schier AF, Neuhauss SC, Harvey M, Malicki J, Solnica-Krezel L, Stainier DY, Zwartkruis F, Abdelilah S, Stemple DL, Rangini Z, Yang H, Driever W
(1996) Mutations affecting the development of the embryonic zebrafish brain. Development 123:165-178.

Schwartzkroin PA, Walsh CA (2000) Cortical malformations and epilepsy. Ment Retard Dev Disabil Res Rev 6:268-280.

Sloviter RS (1996) Hippocampal pathology and pathophysiology in temporal lobe epilepsy. Neurologia 11 [Suppl 4]:S29-S32.

Tang R, Dodd A, Lai D, McNabb WC, Love DR (2007) Validation of zebrafish (Danio rerio) reference genes for quantitative real-time RT-PCR normalization. Acta Biochim Biophys Sin (Shanghai) 39:384-390.

Thom M, Martinian L, Parnavelas JG, Sisodiya SM (2004) Distribution of cortical interneurons in grey matter heterotopia in patients with epilepsy. Epilepsia 45:916-923.

Thompson JD, Higgins DG, Gibson TJ (1994) CLUSTAL W: improving the sensitivity of progressive multiple sequence alignment through sequence weighting, position-specific gap penalties and weight matrix choice. Nucleic Acids Res 22:4673-4680.

Vanegas H, Ebbesson SO (1976) Telencephalic projections in two teleost species. J Comp Neurol 165:181-195.

van Kammen DP, Petty F, Kelley ME, Kramer GL, Barry EJ, Yao JK, Gurklis JA, Peters JL (1998) GABA and brain abnormalities in schizophrenia. Psychiatry Res 82:25-35.

Vezzani A, Sperk G, Colmers WF (1999) Neuropeptide Y: emerging evidence for a functional role in seizure modulation. Trends Neurosci 22:25-30.

Westerfield M (1993) The zebrafish book: a guide for the laboratory use of zebrafish (Brachydanio rerio). Eugene, OR: Westerfield.

Williams SN, Locke CJ, Braden AL, Caldwell KA, Caldwell GA (2004) Epileptic-like convulsions associated with LIS-1 in the cytoskeletal control of neurotransmitter signaling in Caenorhabditis elegans. Hum Mol Genet 13:2043-2059.

Wu Y, Bolduc FV, Bell K, Tully T, Fang Y, Sehgal A, Fischer JA (2008) A Drosophila model for Angelman syndrome. Proc Natl Acad Sci U S A 105:12399-12404.

Wullimann MF, Rupp B, Reichert H (1996) Neuroanatomy of the zebrafish brain: a topological atlas. Basel: Birkhäuser Verlag.

Xi ZQ, Xiao F, Yuan J, Wang XF, Wang L, Quan FY, Liu GW (2009) Gene expression analysis on anterior temporal neocortex of patients with intractable epilepsy. Synapse 63:1017-1028.

Xu Q, Cobos I, De La Cruz E, Rubenstein JL, Anderson SA (2004) Origins of cortical interneuron subtypes. J Neurosci 24:2612-2622.

Yoshimura M, Nishi S (1982) Intracellular recordings from lateral horn cells of the spinal cord in vitro. J Auton Nerv Syst 6:5-11.

Zuker M (2003) Mfold web server for nucleic acid folding and hybridization prediction. Nucleic Acids Res 31:3406-3415. 